Document downloaded from:

http://hdl.handle.net/10251/94889

This paper must be cited as:

Vandegehuchte, BD.; Thybaut, JW.; Martinez Feliu, A.; Arribas Viana, MDLD.; Marin, GB. (2012). n-Hexadecane hydrocracking Single-Event MicroKinetics on Pt/H-beta. Applied Catalysis A General. 441:10-20. doi:10.1016/j.apcata.2012.06.054

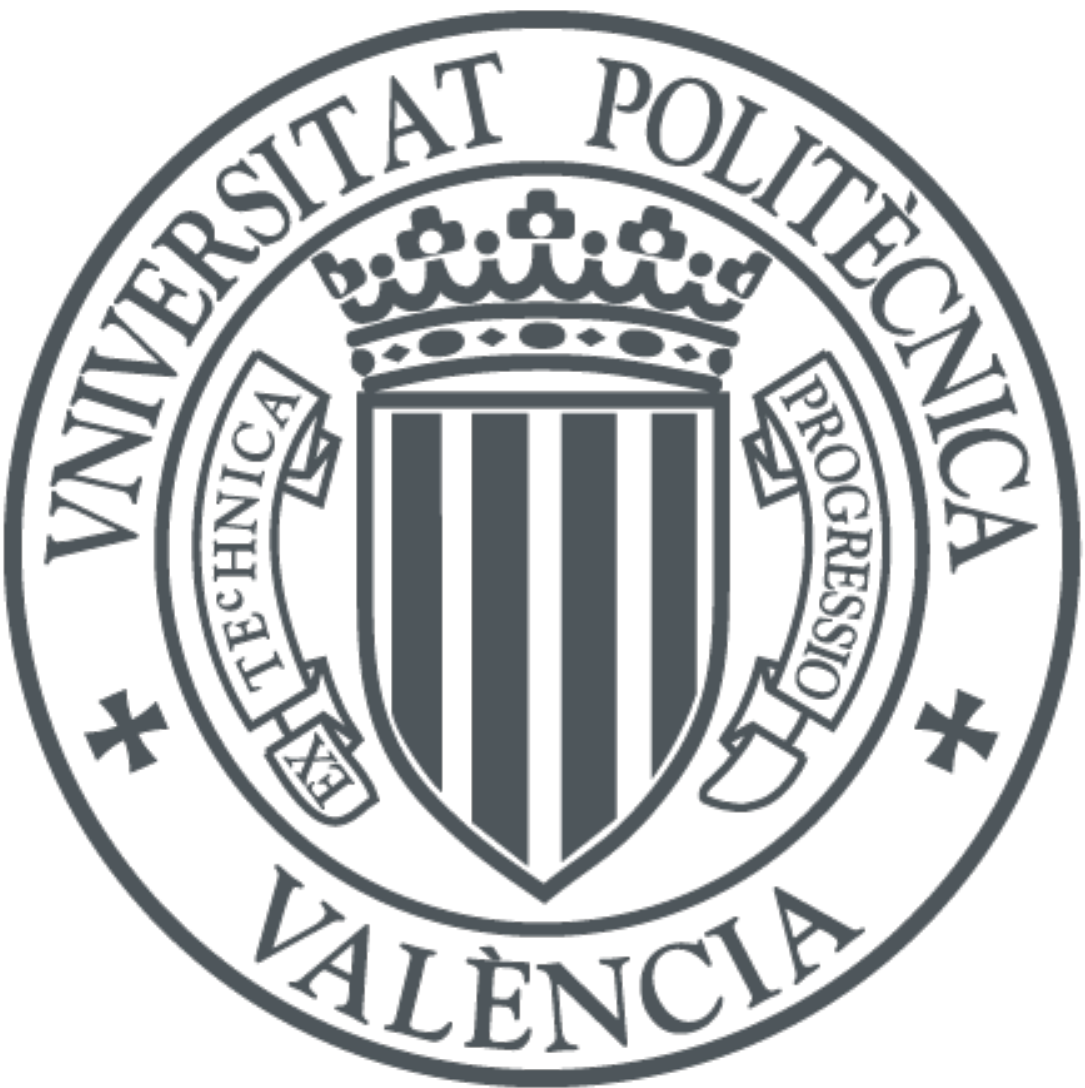

The final publication is available at

https://doi.org/10.1016/j.apcata.2012.06.054

Copyright Elsevier

Additional Information 


\title{
n-Hexadecane Hydrocracking Single-Event Microkinetics on Pt/H-Beta
}

\author{
B.D. Vandegehuchte ${ }^{a}$, J.W. Thybaut ${ }^{\mathrm{a},}{ }^{*}$, A. Martínez ${ }^{\mathrm{b}}$, M.A. Arribas ${ }^{\mathrm{b}}$, G.B. Marin ${ }^{\mathrm{a}}$ \\ a Laboratory for Chemical Technology, Chemical Engineering Department, Ghent \\ University, Krijgslaan 281-S5, Gent B-9000, Belgium

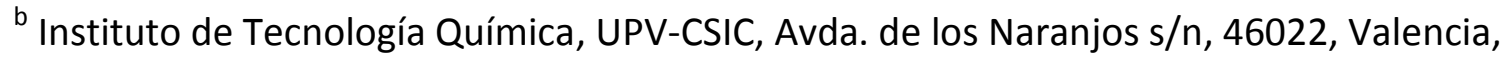 \\ Spain
}

*Corresponding author. Tel.: + 32926455 63. E-mail adress: Joris.Thybaut@UGent.be 


\section{Abstract}

The Single-Event MicroKinetic (SEMK) model constructed for gas-phase hydroconversion of light $n$-alkanes on large-pore USY zeolites was applied, for the first time, to the hydrocracking of $n$-hexadecane on a Pt/H-Beta catalyst. Despite the 12 -ringed pore channels, shape selectivity was observed in the formation of ethyl side chains.

Additionally, heavy feed molecules such as $n$-hexadecane lead to physisorption saturation of the catalyst pores by strong Van der Waals interactions of the long alkyl chains with the zeolite framework. Intermolecular interactions and packing efficiencies in the pores induce deviations from typical Henry-regime physisorption characteristics as the physisorption selectivity, which is expected to increase with increasing carbon number, appeared to be independent of the latter. Micropore saturation effects were described by the 'size entropy' which quantifies the difference in standard entropy loss between physisorption in the Henry regime and hindered physisorption on a saturated surface. The size entropy is proportional to the catalyst loading with physisorbed species and the adsorbate carbon number. The addition of a size entropy term in the SEMK model, amounting to $102 \mathrm{~J} \mathrm{~mol}^{-1} \mathrm{~K}^{-1}$ for a hexadecane molecule at full saturation, allowed accurately reproducing the contribution of secondary isomerization and cracking reactions, as quantified by means of a contribution analysis. 


\section{Introduction}

Stringent environmental regulations impose restrictions on fuel emissions and demand for advanced post treatments for the removal of harmful compounds. Hydrocracking is a wellknown refinery process which increases the overall quality of heavy hydrocarbon mixtures by means of consecutive isomerization and cracking reactions [1]. Desulfurization, denitrogenation and dearomatization typically precede hydrocracking reactions and give rise to the 'clean' reputation of hydroprocessed products which is a great stimulus for the utilization of hydroconversion units in residue upgrading [2, 3]. Hydrocracking is also ideally suited for the production of high-value middle distillates from Fischer-Tropsch (FT) waxes. The latter typically consist of long normal alkanes which is limiting their use as fuel or lubricant. The resulting hydrocracking products are characterized by high cetane numbers, attractive emission properties and improved cold-flow properties $[4,5]$.

Hydrocracking of hydrotreated product streams and FT waxes is usually carried out over a zeolite carrier provided with a noble metal, e.g., platinum and/or palladium. The metal introduces a (de)-hydrogenation function into the catalyst that enables the transformation of a physisorbed alkane into an unsaturated alkene. Chemisorption of the latter on a Brønsted acid site results in an alkylcarbenium ion that is susceptible to skeleton rearrangements and cracking towards lighter hydrocarbons. Finally, product ions and alkenes are respectively deprotonated and hydrogenated [6, 7]. 
Various molecular sieves have already been applied in hydroconversion processes. Both the structure of the zeolite pore network and the framework aluminium concentration may significantly affect the catalytic activity and/or selectivity towards isomer and cracked products [8-14]. Hydrocracking on faujasites occurs via an unconstrained reaction network and leads to a wide product distribution, while on zeolites with a narrower pore structure such as TON-type frameworks, the pore access for and the formation of bulky hydrocarbons is typically restricted by shape-selective effects. In the case of ZSM-22 zeolite (TON structure), so-called pore mouth and key lock catalysis determine the peculiar isomerization selectivity [15]. Other medium-pore zeolites such as ZSM-5 (MFI) are characterized by their excessive cracking behaviour owing to their typical zig-zag channel configuration with relatively large intersections and narrower interconnections [16-19].

A fundamental Single-Event MicroKinetic (SEMK) methodology has been developed to describe the complex reaction mechanism in gas-phase hydroconversion of $n$-alkanes over large-pore USY zeolites [20-23], and has later been extended to deal with extreme shape selectivity [24] and also bulk-phase non-idealities encountered during liquid hydrocracking $[25,26]$. For other well-known large-pore zeolites, such as mordenite and beta, a fundamental microkinetic model has not yet been constructed. In addition, saturation effects during gas-phase hydrocracking, which essentially forms the transition regime from the Henry physisorption region established during light-alkane conversion, to full 
micropore saturation during liquid-phase reactions, has not yet been a modelling point of investigation up to date. In the former case, physisorption of light alkanes in the zeolite pores can be described by Henry's law assuming Van der Waals interactions between hydrocarbon and zeolite only [27], whereas repulsion forces between adsorbate molecules need to be accounted for under full saturation conditions and induce significant deviations from the Henry regime $[28,29]$.

Large-pore beta (BEA) zeolite has already been extensively used for experimental hydroconversion studies and generally showed a similar product distribution as was obtained on a USY zeolite. Differences in activity could be attributed to differences in physisorption stabilization and acidity rather than to structural constraints caused by the pore structure [30-33]. However, the formation of ethyl side chains in beta zeolites was limited in experimental $n C_{10}-n C_{17}$ hydrocracking data reported by Martens et al. [34] and resulted in lower yields of ethyl-branched species. The beta zeolite framework is built up from straight 12 -membered pore channels $(0.77 \mathrm{~nm} \times 0.66 \mathrm{~nm})$ interconnected through sinusoidal channels $(0.56 \mathrm{~nm} \times 0.56 \mathrm{~nm})$. Cavities of about 1.2-1.3 nm are present at the channel intersections. The 3-dimensional framework of a USY zeolite contains wider pore windows $(0.74 \mathrm{~nm} \times 0.74 \mathrm{~nm})$ and so-called 'supercages' with dimensions that are similar to the beta cavities $[35,36]$. As a result, shape selectivity in the formation of bulkier components, if any, will occur on BEA rather than on FAU. 
In this work, the Single-Event MicroKinetic (SEMK) model originally constructed for hydroisomerization of light $n$-octane on a commercial USY zeolite [23], was extended to gas-phase hydrocracking of $n$-hexadecane on a beta-type catalyst. The contribution of ethyl-branched species in the reaction network of $n$-hexadecane hydrocracking is substantially higher and, consequently, allows a more distinct assessment of the difference in hydrocracking behaviour between both zeolites. Special attention was also required by the large size of the feed molecule that was investigated at gas-phase conditions. Due to the very pronounced physisorption stabilization induced by the reactant's size, other interactions apart from the classical Van der Waals forces between adsorbate and adsorbent might emerge and significantly affect the resulting product distribution. A general methodology is aimed at which is able to describe the alkane physisorption behaviour in all three regimes, i.e. at low adsorbate concentrations, at high adsorbate concentrations under gas-phase conditions, and at full saturation during liquidphase reactions.

\section{Procedures and model equations}

\subsection{Preparation and properties of Pt/H-beta catalyst}

The Pt/H-beta catalyst (1 wt\% Pt nominal loading) was prepared by wetness impregnation of a commercial $\mathrm{H}$-beta sample (CP811 from Zeolyst International) with a $0.2 \mathrm{~N}$ aqueous solution of hexachloroplatinic acid $\left(\mathrm{H}_{2} \mathrm{PtCl}_{6} \cdot 6 \mathrm{H}_{2} \mathrm{O}\right.$, Sigma-Aldrich), followed by drying at

$373 \mathrm{~K}$ overnight and subsequent calcination in a muffle oven at $773 \mathrm{~K}$ for $3 \mathrm{~h}$. 
B.E.T. surface area and micropore volume values of $607 \mathrm{~m}^{2} \mathrm{~g}^{-1}$ and $0.21010^{-6} \mathrm{~m}^{3} \mathrm{~g}^{-1}$, respectively, were obtained for $\mathrm{H}$-beta by $\mathrm{N}_{2}$ physisorption at $77 \mathrm{~K}$, both values being in good agreement with those expected for a high-quality BEA zeolite [32]. The bulk Si/AI ratio and Pt content of the calcined Pt/H-beta catalyst were, respectively, 12 and 0.97 wt\% as determined by ICP-OES in a Varian 715-ES apparatus after dissolution of the solid in an $\mathrm{HNO}_{3}: \mathrm{HF}: \mathrm{HCl}$ acid mixture (1:1:3 volume ratio). The total amount of acid sites in the $\mathrm{H}$ beta zeolite was $5.5710^{-4} \mathrm{~mol} \mathrm{~g}^{-1}$ as determined by $\mathrm{NH}_{3}$-TPD. The Pt dispersion in the calcined Pt/H-beta sample was $42 \%$ as measured by $\mathrm{H}_{2}$ chemisorption at $313 \mathrm{~K}$ by using the double isotherm method on a Quantachrome Autosorb-1 equipment after in situ reduction of the sample at $673 \mathrm{~K}$ for $2 \mathrm{~h}$ under pure hydrogen flow, assuming a $\mathrm{H}: \mathrm{Pt}$ adsorption stoichiometry of 1:1.

For comparison purposes, a Pt/H-USY catalyst was also prepared from a NaY sample (CBV100, Zeolyst International) through two consecutive $\mathrm{NH}_{4}{ }^{+}$exchanges, a two-step steaming at $873 \mathrm{~K}$ for $3 \mathrm{~h}$ and at $1023 \mathrm{~K}$ for $5 \mathrm{~h}$ with an intermediate $\mathrm{NH}_{4}{ }^{+}$exchange step. The bulk and framework Si/AI atomic ratios for the final USY zeolite were 2.6 and 16.6, respectively. Provision with Pt occurred through the same procedure as earlier described for the beta zeolite.

Prior to catalysis, the Pt/H-beta and the Pt/H-USY catalyst were reduced in situ in flowing pure hydrogen $\left(0.018 \mathrm{~m}^{3} \mathrm{~h}^{-1}\right)$ at atmospheric pressure and at a temperature of $673 \mathrm{~K}$ for 2 
h. This pretreatment ensured a total reduction of the PtO species present in the calcined materials to metallic Pt, as ascertained by $\mathrm{H}_{2}$-TPR and XPS measurements of the reduced samples (not shown).

\subsection{Hydrocracking experiments}

A total of $23 n$-hexadecane hydrocracking experiments was carried out in a tubular continuous flow reactor packed with catalyst pellets with diameters ranging between 0.25 and $0.42 \mathrm{~mm}$. The experimental setup is described elsewhere [37, 38]. The space time ranged from 20 to $232 \mathrm{~kg} \mathrm{~s} \mathrm{~mol}^{-1}$. The reaction temperature was varied between 503 and $523 \mathrm{~K}$ while the reactor pressure was set equal to either $0.5,1$ or $2 \mathrm{MPa}$. The inlet hydrogen-to-hydrocarbon molar ratio was 100 in each of the experiments. No indications for hydrogenolysis and primary carbenium ion chemistry were found as evidenced by the negligible methane, ethane, $\mathrm{C}_{14}$ and $\mathrm{C}_{15}$ alkanes formation. The total conversion is defined as:

$$
X=\frac{F_{n C_{16}}^{0}-F_{n C_{16}}}{F_{n C_{16}}^{0}}
$$

Yields are defined as:

$$
Y_{i}=\frac{F_{i}}{F_{n C_{16}}^{0}}
$$

No evident catalyst deactivation, at least within the range of the investigated time-on stream ( 4 to $8 \mathrm{~h}$ ), was observed in the whole range of reaction conditions studied, even at the lowest total pressure of $0.5 \mathrm{MPa}$, vide Figure 1 . The high stability of the Pt/H-beta 
catalyst suggests that the amount of accessible metallic Pt sites is sufficiently high for ensuring a fast hydrogenation of the sorbed intermediates, hence, preventing consecutive acid-catalyzed reactions which promote coking.

Ideal plug flow inside the reactor tube can be assumed as the criteria for the absence of axial and radial dispersion effects are satisfied in the entire range of operating conditions $[39,40]$. Also, the Wheeler-Weisz modulus and the Carberry number for internal and external mass transport limitations remain sufficiently low $[41,42]$. Consequently, it could reasonably be assumed that intrinsic kinetic data were acquired during each experiment.

Prior to kinetic modelling, each experiment was screened for the occurrence of 'ideal hydrocracking', i.e. the quasi-equilibration of the (de)-hydrogenation reactions and, hence, the rate-determining character of the acid-catalyzed reactions [7, 12, 43]. Quasiequilibration of the (de)-hydrogenation reactions implies a negative effect of the total pressure on the total conversion of the feed component which, consequently, is a useful tool in the distinction of ideal from non-ideal hydrocracking. Additionally, a unique relationship is observed between the isomer yield and the total conversion. Finally, a maximum insight in the acid-catalyzed reaction mechanism is obtained. The establishment of ideal hydrocracking conditions depends on the catalyst as well as on the operating conditions and the feed. Low pressures, high temperatures, high inlet hydrogen-tohydrocarbon molar ratios and heavy feed molecules are found to favour non-ideality [43, 
44]. Figure 2 shows all experimentally obtained isomer yields as a function of the total $n \mathrm{C}_{16}$ conversion. Deviations from the ideal regime become more pronounced at higher conversions, especially at $523 \mathrm{~K}$ where an isomerization yield of only $17.8 \%$ was obtained at a total conversion exceeding $85 \%$. In addition, the experiments performed at $0.5 \mathrm{MPa}$ exhibited a significantly lower hexadecane isomer yield regardless of the total $n C_{16}$ conversion. Based on Figure 2, 18 out of the 23 experiments were selected for regression analysis by means of a SEMK model assuming ideal hydrocracking conditions.

\subsection{Parameter estimation}

A robust approximation of the real parameter values was obtained by use of a Rosenbrock algorithm [45]. The Levenberg-Marquardt method was applied afterwards for final optimization [46]. An in-house written code was used for the Rosenbrock method, while the ordinary least squares (OLS) option of the ODRPACK version 2.01, available at NETLIB, was selected for the Marquardt algorithm [47]. Extra code was incorporated in order to retrieve some statistical information.

The weighed sum of squared differences between the experimental and the calculated outlet flow rates was minimized by adjusting the model parameter vector $\boldsymbol{b}$ which in turn approaches the real parameter vector $\boldsymbol{\beta}$ at the optimum.

$$
\mathrm{SSQ}=\sum_{j=1}^{n o b s} \sum_{i=1}^{n r e s p} w_{i}\left(F_{i, j}-\hat{F}_{i, j}\right)^{2} \stackrel{\boldsymbol{b}}{\longrightarrow} \operatorname{Min}
$$


The weighing factors $w_{i}$ are the diagonal elements of the inverse of the variancecovariance matrix of the experimental errors on the responses. In case there are no replicate experiments available, this matrix was estimated from the outlet flow rates according to the following equation:

$$
w_{i}=\frac{\left(\sum_{k=1}^{n o b s} F_{i, k}\right)^{-1}}{\sum_{j=1}^{n r e s p}\left(\sum_{k=1}^{n o b s} F_{j, k}\right)^{-1}}
$$

Lumping or relumping was not performed as the GC analysis of the effluent allowed a detailed description of the product distribution [26, 48, 49]. Product yields of the individual multibranched components up to carbon number 7 could be distinguished as well as monobranched species up to carbon number 16. For SSQ minimization, vide Equation 3, a total of 23 responses was defined according to the branching degree and carbon number. For hexadecane, a distinction was made between mono-methyl, monoethyl and multibranched isomers.

\subsection{Reactor model}

An isothermal operation of the plug flow reactor was assumed and a negligible pressure drop was estimated by Ergun's equation [50]. As a result, using a pseudohomogeneous one-dimensional reactor model, a set of ordinary differential equations is obtained with the molar flow rates of each reaction product $i$ as independent variables.

$$
\frac{\mathrm{d} \hat{F}_{i}}{\mathrm{~d} W}=R_{i}
$$


The integration of this set of ordinary differential equations yields the molar outlet flow rate of each product and was performed by use of the DVODE subroutine available at NETLIB [47]. The flow rates of the feed component and hydrogen were determined from respectively the carbon and the hydrogen atom balance.

\subsection{Kinetic model}

\subsubsection{Single-Event MicroKinetic (SEMK) methodology}

The $n$-hexadecane hydrocracking reaction network comprises about 24,000 hydrocarbons interconnected by close to 90,000 (de)-hydrogenation, (de)-protonation, isomerization and cracking elementary steps. Only the acid-catalyzed isomerization and cracking reactions are considered to be rate-determining. Quasi-equilibrium is assumed for the (de)-protonation and the (de)-hydrogenation steps, the latter corresponding to ideal hydrocracking, vide Paragraph 2.2.

In order to avoid a huge number of kinetic coefficients to be determined while retaining the molecular detail in the model, the SEMK methodology was used which, in essence, is based on the reaction family concept rather than assigning an individual kinetic coefficient to each elementary step considered in the network [21]. Reaction families are defined based on the type of elementary step, i.e., alkyl shift (AS), PCP branching (PCP) and $\beta$ scission ( $\beta)$, and on the type of carbenium ions involved in the reaction as reactant and product, i.e., secondary and/or tertiary [51]. 
Within a single reaction family, symmetry effects may cause differences between the rate coefficients of elementary steps. As a result, a unique, single-event rate coefficient, $\widetilde{k}$, is obtained per family which differs from the actual rate coefficient of an elementary step by a factor corresponding to the so-called 'number of single events', $n_{e}$, i.e., a factor quantifying the number of structurally identical pathways through which an elementary step can occur. For an isomerization or cracking reaction starting from ion type $m_{1}$ and yielding ion type $m_{2}$, the rate coefficient is expressed as the product of a kinetic and a structural factor [20]:

$$
k_{m_{1} ; m_{2}}^{\mathrm{AS} / \mathrm{PCP} / \beta}=n_{e} \widetilde{k}_{m_{1} ; m_{2}}^{\mathrm{AS} / \beta}
$$

$n_{e}$ is determined from the global symmetry numbers of the reactant and the transition state:

$$
n_{e}=\frac{\sigma_{\mathrm{R}^{+}}}{\sigma_{\neq}}
$$

\subsubsection{Rate equation}

Using a Langmuir isotherm for the physisorption step yields a typical expression for the rate of an acid-catalyzed step, with carbenium ion $k$ as reactant formed out of olefin $j$, in turn originating from alkane $i$, and producing carbenium ion $q$ originating from alkene $r$. 


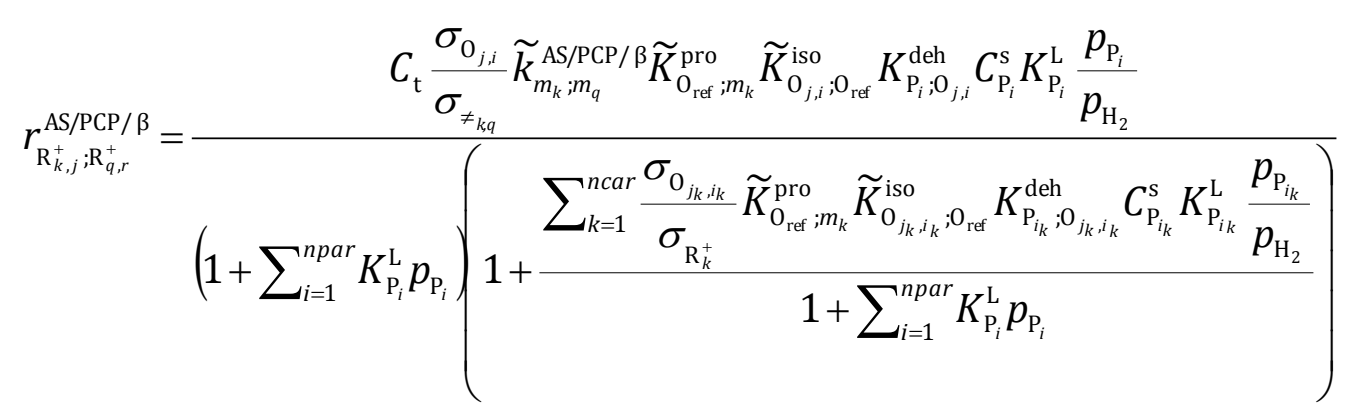

This expression is somewhat more complex than previously used SEMK rate equations [20,

$21,51]$ because the carbenium ion concentrations on the acid sites are not neglected [23]. The parameters in Equation 8 are explained in the Nomenclature. Some parameters such as the single-event isomerization coefficients and the dehydrogenation equilibrium coefficients, were calculated from the pure component thermodynamic properties, the latter being calculated using Benson's group contribution method [52].

Applying the pseudo steady-state approximation for the alkene and carbenium ion intermediates, the net rate of formation of an alkane can be obtained from the sum of the net rates of formation of all carbenium ions and alkenes with a carbon skeleton that is identical to that of the alkane. The alkenes in this expression are those that are directly formed via $\beta$-scission.

$$
R_{\mathrm{P}_{i}}=\sum_{j} R_{\mathrm{O}_{j, i}}^{\beta}+\sum_{k} R_{\mathrm{R}_{k, i}^{+}}^{\mathrm{AS} / \mathrm{PCP} / \beta}
$$

\subsubsection{Catalyst and kinetic descriptors}

Equation 8 contains parameters which depend on the catalyst type, i.e., the acidity of the catalyst, the alkane saturation concentration, the Langmuir physisorption coefficient and 
the protonation equilibrium coefficients, and are denoted as 'catalyst descriptors'. The total acid site concentration was determined at a value of $5.5710^{-4} \mathrm{~mol} \mathrm{~g}^{-1}$, vide Paragraph 2.1. The saturation concentration was approximated by the ratio of the catalyst micropore volume and the liquid molar volume of the alkane at the reaction temperature, the latter calculated using the Hankinson-Brobst-Thomson method [53]. The experimentally obtained micropore volume of $0.21010^{-6} \mathrm{~m}^{3} \mathrm{~g}^{-1}$ was used. The Langmuir physisorption coefficient is calculated from the Henry coefficient which in turn is calculated from the standard physisorption enthalpy $\Delta H_{\text {phy }}^{0}$ and entropy $\Delta S_{\text {phy }}^{0}$ [54]:

$$
K^{\mathrm{L}}=\frac{H}{C^{\mathrm{s}}}=0.5 p^{0} \mathrm{e}^{\frac{\Delta S_{\text {phy }}^{0}}{R}} \mathrm{e}^{\frac{-\Delta H_{\text {phy }}^{0}}{R T}}
$$

At low loadings, the standard physisorption enthalpy and entropy were found to be a linear function of the carbon number of the physisorbed molecule on zeolites FAU, BEA, MFI and TON $[27,55,56]$. On a beta zeolite of a similar Si/Al ratio, the following expressions were reported [56]:

$$
\begin{aligned}
& -\Delta H_{\mathrm{phy}}^{0}=10.0 C N+2.6 \mathrm{~kJ} \mathrm{~mol}^{-1} \\
& -\Delta S_{\mathrm{phy}}^{0}=8.13 C N+36.2 \mathrm{~J} \mathrm{~mol}^{-1} \mathrm{~K}^{-1}
\end{aligned}
$$

Compared to a (US)Y zeolite, the narrower pore channels of beta lead to stronger Van der Waals interactions between the hydrocarbon and zeolite which overcompensate the higher loss in entropy on the latter zeolite. Therefore, beta is a stronger adsorbent than any faujasite. 
A higher selectivity towards the physisorption of linear alkanes was observed compared to the isomers of the same carbon number. This was also concluded from molecular simulations, whereas for faujasites only minor differences in selectivity were measured or calculated $[27,57]$. Nevertheless, a single set of physisorption parameters was maintained per carbon number in order to reduce the global complexity of the model [27].

The average acid strength of the active sites was quantified by the standard protonation enthalpy of olefins leading to secondary and tertiary carbenium ions, independent of the chain length and the branching degree of the olefin [51]. Initial estimates were taken from the modelling results of $n$-octane hydrocracking on a reference USY zeolite $(\mathrm{Si} / \mathrm{Al}=30)$ [23].

The 'kinetic descriptors' comprise the single-event rate coefficients and are independent of the catalyst involved [51]. Ten activation energies were considered for the calculation of 12 single-event rate coefficients with initial values taken from Thybaut et al. [23].

\subsubsection{Relative contributions of reaction rates}

Per component $i$, the differential disappearance factor leading towards component $j$ is defined as the corresponding reaction rate relative to the sum of all reaction rates of all steps with $i$ as a reactant:

$$
\varphi_{i, j}^{\mathrm{d}}=\frac{r_{i, j}}{\sum_{k} r_{i, k}}
$$


The differential formation factor is defined from the reaction rates of the elementary steps which lead to the formation of component $i$ :

$$
\varphi_{i, j}^{\mathrm{f}}=\frac{r_{j, i}}{\sum_{k} r_{i, k}}
$$

\section{Results and discussion}

\subsection{Experimental data and assessment using the original SEMK model}

Experimental results show an increasing total $n$-hexadecane conversion with the space time and reaction temperature, Figure 3. A significant decrease in conversion was measured with an increasing pressure from 1 to $2 \mathrm{MPa}$. A maximum monobranched isomer yield of $22 \%$ was obtained at a total conversion of about $50 \%$, shown in Figure 4 , after which further isomerization towards multibranched species is more preferred due to the significantly reduced concentration of $n \mathrm{C}_{16}$. Formation of tribranched hexadecanes was not evident from the experimental data due to their high reactivity towards cracking $[8,58]$.

At a low total conversion of $5 \%$, Martens et al. [34] observed only minor differences in cracking product distributions between a Pt/H-USY and a Pt/H-beta catalyst for $n$-alkane feeds of varying carbon number, and which were characterized by equal yields of the products which are simultaneously formed out of a feed isomer via cracking. At a higher conversion of $43 \%$, a similar product distribution was not obtained from liquid-phase $n C_{16}$ 
hydrocracking data reported by Park et al. [30]. In that work, full saturation of the micropores combined with a very high reaction temperature of $623 \mathrm{~K}$ apparently enhanced consecutive $\beta$-scissions of cracked products and, hence, increased the selectivity towards the lightest components in $\mathrm{Pt} / \mathrm{H}-$ beta. A similar cracked product distribution was obtained from the data reported in this work at a relatively high total conversion of $76 \%$, vide Figure 5 , indicating that saturation effects could also be responsible for the high yields of $\mathrm{C}_{4}$-to- $\mathrm{C}_{6}$ components.

Comparison of the cracked product distributions of both the $\mathrm{Pt} / \mathrm{H}-\mathrm{beta}$ and the $\mathrm{Pt} / \mathrm{H}-\mathrm{USY}$ zeolite used in this work shows a shift towards the lower molecular weight products $\left(\mathrm{C}_{4^{-}}\right.$ $\mathrm{C}_{7}$ ) only for the former catalyst, vide Figure 6 at a high conversion of $77 \%$. On Pt/H-USY, a more uniform distribution centered at $C_{7}-C_{9}$ is obtained which implies that cracking of secondary products remains absent. Considering the more confining pore structure of a beta framework, which generally leads to stronger physisorption than on a USY zeolite, saturation of the former zeolite is more likely to occur. The latter provides an explanation for the higher observed reactivity of $\mathrm{C}_{8}-\mathrm{C}_{12}$ products as will be discussed later in Paragraph 3.2 .

In order to assess the effect of a different zeolite topology and the use of a heavy feed component in gas-phase reactions, the SEMK model developed for and applied to gasphase conversion of light alkanes over faujasites which uses Equation 8 for the reaction 
rate of an acid-catalyzed step, was employed for the simulation of the current data set.

When neglecting any intermolecular interactions in the physisorption model, Equation 10 can be used for the calculation of the physisorption coefficient. Table 1 shows the estimated values for the standard protonation enthalpies and the activation energies of the acid-catalyzed isomerization and cracking steps. A satisfactory reproduction of the total $n \mathrm{C}_{16}$ conversion could be obtained at varying process conditions, vide Figure 3 . The calculated yields of monobranched as well as of multibranched $\mathrm{C}_{16}$ isomers also approached the experimental value quite well as shown in Figure 4.

Table 1 - Estimated values for the standard protonation enthalpies $\Delta H^{\text {pro }}$ for secondary (s) and tertiary (t) carbenium ion formation, and activation energies $E_{\text {act }}$ for isomerization (ALS and PCP) and cracking steps $(\beta)$ in $\mathrm{kJ} \mathrm{mol}^{-1}$. Original model, applying Equations 8 and 9 for respectively the reaction rates and the alkane net production rates. Advanced model, additionally incorporating Equation 15 and Equations 21 to 23 for respectively the formation of ethyl branches and the size entropy.

\begin{tabular}{c|c|c}
\hline Parameter & original model & advanced model \\
\hline$\Delta H^{\mathrm{pro}}(\mathrm{s})$ & $-69.3( \pm 0.2)^{\mathrm{a}}$ & $-72.6( \pm 0.8)$ \\
$\Delta H^{\mathrm{pro}}(\mathrm{t})$ & $-104.1( \pm 0.5)$ & $-102.7( \pm 1.6)$ \\
\hline$E_{a c t}^{\mathrm{AS}}(\mathrm{s}, \mathrm{s})$ & $81.6( \pm 0.3)$ & $79.8( \pm 0.1)$ \\
$E_{\text {act }}^{\mathrm{AS}}(\mathrm{s}, \mathrm{t})^{\mathrm{b}}$ & $76.8( \pm 1.4)$ & $74.8( \pm 2.7)$ \\
$E_{\text {act }}^{\mathrm{AS}}(\mathrm{t}, \mathrm{t})$ & $104.5^{\mathrm{c}}$ & $104.5^{\mathrm{c}}$ \\
$E_{\text {act }}^{\mathrm{PCP}}(\mathrm{s}, \mathrm{s})$ & $109.2( \pm 0.3)$ & $112.1( \pm 1.8)$ \\
$E_{\text {act }}^{\mathrm{PCP}}(\mathrm{s}, \mathrm{t}) \mathrm{b}$ & $92.6( \pm 0.4)$ & $93.3( \pm 1.2)$ \\
$E_{a c t}^{\mathrm{PCP}}(\mathrm{t}, \mathrm{t})$ & $124.1( \pm 0.7)$ & $125.5( \pm 2.2)$ \\
$E_{a c t}^{\beta}(\mathrm{s}, \mathrm{s})$ & $142.0( \pm 2.0)$ & $138.9( \pm 1.6)$ \\
$E_{a c t}^{\beta}(\mathrm{s}, \mathrm{t})$ & $118.1( \pm 2.2)$ & $122.8( \pm 6.8)$ \\
$E_{a c t}^{\beta}(\mathrm{t}, \mathrm{s})$ & $152.2( \pm 1.2)$ & $149.5( \pm 2.3)$
\end{tabular}




\begin{tabular}{c|c|c}
$E_{\text {act }}^{\beta}(\mathrm{t}, \mathrm{t})$ & $125.1^{\mathrm{c}}$ & $125.4( \pm 2.3)$ \\
\hline $\mathrm{a} 95 \%$ confidence interval & ${ }^{\mathrm{b}} E_{\text {act }}(\mathrm{t}, \mathrm{s})=E_{\text {act }}(\mathrm{s}, \mathrm{t})+\Delta H^{\text {pro }}(\mathrm{s})-\Delta H^{\text {pro }}(\mathrm{t})^{\mathrm{c}}$ non-significant parameter
\end{tabular}

Indications for shape-selective effects were found from the parity diagram for the outlet molar flow rates of mono-ethyl branched hexadecane isomers as shown in Figure 7-a. The calculated outlet flow rates were about one order of magnitude higher than experimentally obtained. The formation of an ethyl branch occurs via an alkyl shift involving a change in position of a bulky side chain with the charge. Apparently, the somewhat narrower pore structure of a beta zeolite and/or the absence of supercages in the framework induced a restricted formation of ethyl-branched isomers which, consequently, could not be reproduced by a SEMK model designed for FAU-type zeolites. An experimental study by Martens et al. [34] already suggested possible shape-selective behaviour of a beta zeolite in the formation of ethyl side chains. An additional contribution to the activation energy of alkyl shift reactions involved in ethyl side chain formation or disappearance, $\Delta E_{\text {act }}$, may suffice to account for these effects:

$$
\widetilde{k}_{m_{1} ; m_{2}}^{\mathrm{AS} \text { eth }}=\widetilde{k}_{m_{1} ; m_{2}}^{\mathrm{AS}} \mathrm{e}^{\frac{-\Delta E_{\text {act }}}{R T}}
$$

Focusing on the cracked product distribution, the formation of the lighter alkanes in the network were generally underestimated in contrast to the yields of the heavier alkanes which were predicted satisfactorily.

Figure 8 visualizes the difference between the modelled and observed pentane and undecane yields calculated according to Equation 2. The observed production of $C_{5}$ alkanes was about twice as high as the production of $\mathrm{C}_{11}$ components while the model predicted equal yields for both products at any set of operating conditions. As mentioned 
above, the experimental data clearly suggested that cracked products, once formed out of a hexadecyl cation, undergo consecutive cracking. Based on the experience with lighter hydrocarbons on a USY zeolite, this possibility was originally not included in the model, leading to equal yields for both components of each 'cracking pair', i.e., $C_{3}$ and $C_{13}, C_{4}$ and $C_{12}, C_{5}$ and $C_{11}, C_{6}$ and $C_{10}$, and $C_{7}$ and $C_{9}$. This is also evident from Figure 5 which shows a symmetric distribution of the molar yields of the cracked products about carbon number 8 even up to high total conversions such as $76 \%$. As already shown in vide Figure 6 , such a uniform cracking product distribution was still recovered from $n$-hexadecane experiments over a Pt/H-USY catalyst.

A similar observation was made in case of the linear and branched product yields within the same carbon number. The production of linear alkanes is generally overestimated as shown for $\mathrm{C}_{8}$ in Figure 9. Apparently, the model does not adequately describe any additional isomerization of linear cracked products towards monobranched isomers.

The shortcoming of the original model in describing the reactivity of lighter components in the reaction network originates from the manner in which physisorption is simulated. At low adsorbate concentrations, the trend of the Langmuir physisorption coefficient, Equation 10, with the carbon number is mainly determined by the enthalpy term and, hence, it can be understood from Equation 11 that, in the Henry regime, physisorption will be most pronounced for the heaviest molecule. Applied to the current experimental data, 
the original model implementation simulated hexadecane compounds to be primarily physisorbed while only negligible $C_{5}-C_{13}$ carbenium ion concentrations were obtained due to the disfavoured physisorption of alkanes with lower carbon number.

\subsection{Development of a physisorption model accounting for micropore}

\section{saturation}

At low catalyst loadings, denoted as the Henry regime, the difference in stabilization between physisorbed alkanes is merely related to differences in Van der Waals interactions between the adsorbate and the zeolite lattice, and results in a physisorption step dominated by the heaviest hydrocarbons in the reaction mixture, vide Equations 10 to 12 . Deviations from the Henry regime usually emerge when adsorbate molecules are susceptible to physical interactions with other physisorbed species. The catalyst loading with physisorbed species, $\theta$, is defined as the sum of the concentrations of all physisorbed alkanes relative to the mean saturation concentration $\bar{C}^{\mathrm{s}}$ :

$$
\theta=\frac{\sum_{i} C_{\mathrm{P}_{i}}}{\bar{C}^{\mathrm{s}}}
$$

$\bar{C}^{s}$ being defined as:

$$
\bar{C}^{\mathrm{s}}=\frac{\sum_{i} C_{i}^{\mathrm{s}} C_{\mathrm{P}_{i}}}{\sum_{j} C_{\mathrm{P}_{j}}}
$$

Equation 17 for the mean saturation concentration is slightly different from the definition of Denayer et al. [59], but ensures a value for $\theta$ situated between 0 and 1 . Table 2 shows the catalyst loading at different total $n \mathrm{C}_{16}$ conversions calculated using the original model 
for gas-phase hydrocracking over USY. The concentration of physisorbed species in the zeolite pores initially remains close to the saturation capacity of the catalyst and decreases slightly as the reaction proceeds. A decrease in catalyst loading is explained through the extensive formation of lighter cracking products which, according to Equation 10 , are less stabilized in a subsequent physisorption step. Similar saturation effects were observed during gas-phase physisorption experiments on a faujasite with $n \mathrm{C}_{16}$ as pure feed component and at similar operating conditions [57]. Intermolecular interactions arise at near-saturation loadings and affect the physisorption behaviour of the individual components in such a way that the physisorption selectivity observed at lower loadings, gradually disappears and, ultimately, even may invert $[28,29,59-61]$.

Table 2 - Catalyst loading with physisorbed species at varying total $n \mathrm{C}_{16}$ conversions at $513 \mathrm{~K}, 10$ bar and a space time of $115 \mathrm{~kg} \mathrm{~s} \mathrm{~mol}^{-1}$. Loadings are calculated from the physisorbed alkane concentrations relative to the mean saturation concentration, Equation 16. Physisorbed alkane concentrations are determined from the Langmuir physisorption coefficient, vide Equation 10 to 12.

\begin{tabular}{cc}
\hline$n \mathrm{C}_{16}$ conversion (\%) & coverage (\%) \\
\hline 10 & 100 \\
27 & 99.5 \\
49 & 96.6 \\
75 & 88.8 \\
\hline
\end{tabular}

Denayer et al. [59] introduced a 'Langmuir-with-interactions' expression to incorporate molecular interactions in the physisorption model. Molecular interactions are calculated 
as the product of the catalyst loading and an interaction parameter, $w_{i}$, which depends on the carbon number of the alkane $i$ :

$$
C_{\mathrm{P}_{i}}=\frac{C_{\mathrm{P}_{i}}^{\mathrm{s}} K_{i}^{\mathrm{L}} p_{\mathrm{P}_{i}} \mathrm{e}^{w_{i} \theta}}{1+\sum_{j=1}^{n p a r} K_{j}^{\mathrm{L}} p_{\mathrm{P}_{i}} \mathrm{e}^{w_{j} \theta}}
$$

However, such an isotherm is empirical in nature and the estimated interaction parameters have no explicit physical meaning. In liquid-phase hydrocracking, a similar competitive physisorption step was modelled by quantifying the non-ideal behaviour of the physisorbed phase with excess parameters and the liquid fugacity coefficients of the individual components in the bulk phase [25]. The physical meaning of these excess parameters was clarified via a Born-Haber cycle and could be applicable at dense vapour phase conditions. Incorporation of the liquid fugacity coefficients, which are lower than 1 following the Redlich-Soave-Kwong methodology [53], in the Langmuir expression resulted in a lower physisorbed alkane concentration than would be expected under ideal gas-phase conditions. Stronger reductions in adsorbate concentrations were observed for the heavier alkanes caused by a substantially lower fugacity coefficient compared to the lightest components. A similar methodology for physisorption under 'dense' conditions could not be followed as the gas phase fugacity coefficients of the bulk phase components exceed 1 at the considered reaction conditions and, hence, do not evolve to values below 1 approaching the liquid phase fugacity coefficients in a continuous manner. As a result, according to the methodology developed to describe liquid phase behaviour, the physisorption selectivity at dense gas phase conditions would even become more 
pronounced for the heaviest alkanes rather than disappear. As a result, an alternative methodology needs to be implemented.

Krishna et al. [62] and Calero et al. [63] quantified competitive physisorption behaviour in zeolites by means of the 'size entropy' and 'configurational entropy'. Size entropy effects at high loadings give rise to an inverse effect in physisorption behaviour with increasing chain lengths and originate from differences in packing efficiencies in the zeolite pores between hydrocarbons of different carbon chain lengths. A significantly higher amount of entropy is lost when a bulkier alkane has to fill up a remaining empty space in the zeolite lattice, and ultimately overcompensates the enthalpy contribution to the physisorption coefficient in Equation 11. In an analogous manner, configurational entropy points to differences in efficiency in adsorbate packing between linear alkanes and the corresponding isomers. Krishna et al. [62] managed to successfully simulate the size and configurational entropy for an alkane mixture consisting up to 8 components over a MFI zeolite. These authors made use of the 'Ideal Adsorbed Solution Theory' (IAST) as formulated by Myers and Prausnitz [64] and which, in essence, applies a Raoult-type relation between the physisorbed and bulk gas-phase species concentrations. However, due to the complexity of the IAST which was reported to lead to vast computational efforts for 8-component mixtures, a simplified version was incorporated in the current SEMK model which has to deal with close to 700 different components in the physisorbed phase. 
The size entropy was incorporated in the expression for the Langmuir physisorption coefficient according to Equation 19.

$$
K^{\mathrm{L}}=0.5 p^{0} \mathrm{e}^{\frac{-\Delta H_{\mathrm{phy}}^{0}}{R T}} \mathrm{e}^{\frac{\Delta S_{\mathrm{phy}}^{0}+\Delta S_{\mathrm{siz}}^{0}}{R}}
$$

A similar adjustment to the physisorption coefficient was implemented in the 'Langmuirwith-interactions' model by Denayer et al. [59], vide Equation 18, and suggests that the size entropy, as implemented in the present work, increases linearly with the catalyst loading $\theta$ :

$$
\mathrm{e}^{\frac{\Delta S_{\text {siz }}^{0}}{R}}=\mathrm{e}^{w \theta}
$$

Krishna et al. [62] determined the adsorption isotherms at room temperature of a mixture of $\mathrm{C}_{1}$ to $\mathrm{C}_{4}$ alkanes on MFI determined via the IAST method and Monte-Carlo calculations. The physisorption selectivities, defined from the ratios of the adsorbate concentrations and, hence, of the physisorption coefficients, also showed a sudden logarithmic decrease with increasing catalyst loading. Deviations from the Henry coefficient became more pronounced as the size of the molecule increased. Again associating Equation 18 with Equation 19, the alkane carbon number dependence of the size entropy was already suggested by the interaction parameter $w_{i}$ as defined by Denayer et al. [59]. 
Following Equation 11 and Equation 12 for the standard physisorption enthalpy and entropy, the size entropy effect was approximated by a linear function of the carbon number:

$$
-\Delta S_{s i z}^{0}=\alpha C N+\beta \quad \mathrm{J} \mathrm{mol}^{-1} \mathrm{~K}^{-1}
$$

No gain in entropy is considered for any hydrocarbon in the physisorbed phase resulting in a size entropy contribution which is either zero or negative and, hence, implying that $\beta$ is lower than or at most equal to zero. At higher $\theta$, size entropy effects are expected to become more pronounced reducing the physisorption coefficient of each alkane to a higher extent. The lighter molecules in the reactant mixture are less susceptible to adsorbate-adsorbate interactions and, hence, their physisorption behaviour is expected to be affected only from a higher loading on. Therefore, parameters $\alpha$ and $\beta$ are likely to increase with the catalyst loading and are consequently implemented as a linear function of $\theta$.

$$
\begin{aligned}
& \alpha=\alpha_{1} \theta+\alpha_{2} \mathrm{~J} \mathrm{~mol}^{-1} \mathrm{~K}^{-1} \\
& \beta=\beta_{1} \theta+\beta_{2} \quad \mathrm{~J} \mathrm{~mol}^{-1} \mathrm{~K}^{-1}
\end{aligned}
$$

A negative value for $\beta$ is obtained when $\beta_{2}$ is negative and when its absolute value exceeds that of $\beta_{1}$. At zero coverage, no deviations from the Henry regime are present for any hydrocarbon implying that $\alpha_{2}$ equals zero. Denayer et al. [65] visualized the transition of the Henry regime towards the saturation regime for a $n \mathrm{C}_{6}$-to- $n \mathrm{C}_{9}$ mixture on three different faujasites. Significant differences in physisorption selectivities between the three 
catalysts demonstrate the dependency of the size entropy on the catalyst type, hence, establishing parameters $\alpha_{1}, \beta_{1}$ and $\beta_{2}$ as catalyst descriptors.

There is no need to implement configurational entropy effects as no differences in selectivity between $n$-alkanes and isomers were reported for a beta zeolite from intermediate loadings on [57].

\subsection{Advanced model accounting for shape selectivity and size entropy}

Parameter $\Delta E_{\text {act }}$ defined in Paragraph 3.1, and parameters $\alpha_{1}, \beta_{1}, \beta_{2}$ defined in Paragraph 3.2, were estimated simultaneously with the standard protonation enthalpies for secondary and tertiary carbenium ion formation. The activation energies for the isomerization and cracking steps were essentially allowed to vary between previously determined confidence intervals and, hence, remained close to the values obtained on a reference USY [23], shown in Table 1 together with the estimates for the standard protonation heats. Both standard protonation enthalpies are about $7 \mathrm{~kJ} \mathrm{~mol}^{-1}$ more negative than the corresponding values obtained for USY (CBV760, Si/AI $=30$ ) implying a higher average acid strength of the active sites on the beta zeolite compared to the reference USY [23]. However, solvation effects which typically occur at dense phases and, consequently, at saturation conditions, might be responsible for these enhanced protonation enthalpies. These effects are denoted as 'protonation excess' and were 
quantified on a similar value of about $-7.8 \mathrm{~kJ} \mathrm{~mol}^{-1}$ for a USY (CBV720, Si/AI = 15) zeolite during liquid-phase hydrocracking $[25,26]$.

Figure 3 shows a good agreement between experimental and modelled catalyst activities at varying reaction conditions. Monobranched and multibranched isomer yields are more adequately simulated with the model accounting for shape selectivity and size entropy than with the original model developed for light alkane hydrocracking over USY, vide Figure 4. The additional activation energy contribution to account for shape-selective effects in ethyl side chain formation, $\Delta E_{a c t}$, amounted to $21.9 \mathrm{~kJ} \mathrm{~mol}^{-1}$, vide Table 3 . The model adequately simulates the outlet flow rates of the mono-ethyl branched hexadecane isomers, vide Figure 7-b.

Considering the cracked product distribution, the advanced model is able to adequately reproduce the trends in the experimental data as the modelled yields of the 'cracking pairs', i.e., $C_{3}$ and $C_{13}, C_{4}$ and $C_{12}$, etc., exhibit a more pronounced formation of the lightest component, vide Figure 8 for the $C_{5}-C_{11}$ pair. A substantial decrease in the Langmuir physisorption coefficient with the carbon number caused by the size entropy increases the relative contribution of secondary products to the reaction scheme and, hence, allowing secondary cracking towards lighter products. This ultimately results in a much improved simulation of the cracked product yields, especially at higher $n$-hexadecane conversions, vide Figure 5 at a total conversion of $76 \%$. Figure 9 shows the increased isomerization 
reactivity of secondary products where the agreement between modelled and experimental $n C_{8}$ yields has greatly improved.

Table 3 - Estimated values for the parameters in the expression for the size entropy effect (Equations 2123) in $\mathrm{J} \mathrm{mol}^{-1} \mathrm{~K}^{-1}$, and for the extra activation energy term in Equation 15 for ethyl-branched isomer formation in $\mathrm{kJ} \mathrm{mol}^{-1}$. The model employs Equation 8 and 9 for respectively the reaction rates and the alkane net production rates.

\begin{tabular}{cc}
\hline$\Delta E_{\text {act }}$ & $21.9( \pm 1.0)^{\mathrm{a}}$ \\
$\alpha_{1}$ & $12.6( \pm 0.1)$ \\
$\beta_{1}$ & $31.1( \pm 0.7)$ \\
$\beta_{2}$ & $-130.4( \pm 2.2)$ \\
\hline \multicolumn{2}{l}{$95 \%$ confidence interval }
\end{tabular}

Considering the cracked product distribution, the advanced model is able to adequately reproduce the trends in the experimental data as the modelled yields of the 'cracking pairs', i.e., $C_{3}$ and $C_{13}, C_{4}$ and $C_{12}$, etc., exhibit a more pronounced formation of the lightest component, vide Figure 8 for the $C_{5}-C_{11}$ pair. A substantial decrease in the Langmuir physisorption coefficient with the carbon number caused by the size entropy increases the relative contribution of secondary products to the reaction scheme and, hence, allowing secondary cracking towards lighter products. This ultimately results in a much improved simulation of the cracked product yields, especially at higher $n$-hexadecane conversions, vide Figure 5 at a total conversion of $76 \%$. Figure 9 shows the increased isomerization reactivity of secondary products where the agreement between modelled and experimental $n C_{8}$ yields has greatly improved.

The estimates for parameters $\alpha_{1}, \beta_{1}$, and $\beta_{2}$ in Equations 21 to 23 for the size entropy, are also reported in Table 3. The change in physisorption selectivity after incorporation of the 
size entropy into the model is quantified by the separation factor $\alpha_{i-j}$ which is defined as the ratio of the Henry coefficients of components $i$ and $j[25,56]$ :

$$
\alpha_{i-j}=\frac{H_{i}}{H_{j}}
$$

The difference in separation factors between the advanced model and the original model, i.e., which assumes physisorption conditions situated in the Henry regime, is represented in Figure 10 with $n$-heptane as reference component. When no size entropy is taken into account, physisorption is dominated by Van der Waals interactions between adsorbate and adsorbent and, hence, a preferential adsorption of heavier $n$-alkanes occurs. The implementation of a size entropy effect via Equation 21 with the coefficients from Table 3, results in a close to non-selective physisorption approximately from carbon number 7 on at the investigated operating conditions. A slight inverse in selectivity is observed from carbon number 8 on.

\subsection{Contribution analysis}

The importance of secondary cracking and isomerization reactions in the overall kinetics was assessed by means of a contribution analysis, which is a useful tool to quantify the relative contribution of an individual reaction path in the overall reaction network.

Figure 11 shows the relative disappearance factors, calculated via Equation 13 , of $n$ hexadecane and its isomers towards other $\mathrm{C}_{16}$ components and cracked products at $513 \mathrm{~K}$ and $1 \mathrm{MPa}$, at a conversion of approximately $50 \%$. Cracked products were lumped according to their carbon number. A distinction was made between heavy, i.e., $C_{8}-C_{13}$, and lighter, i.e., $\mathrm{C}_{3}-\mathrm{C}_{7}$, cracked products. Within the heavy cracked products, linear and 
branched molecules were separately accounted for. The analysis shows a similar isomerization-cracking scheme as was observed during hydroconversion on (US)Y zeolites [43]. After isomerization of $n C_{16}$, cracking of monobranched hexadecane only occurred to a low extent due to the high activation energy for $(s, s) \beta$-scission compared to further PCP branching, vide Table 1 . A significant cracking reactivity of tribranched $\mathrm{C}_{16}$ isomers to especially branched products results from the low activation energy for $(t, t) \beta$-scission. Once formed out of hexadecyl cation, branched cracked products rather undergo additional cracking towards lighter products than debranching to the corresponding linear hydrocarbon.

The occurrence of secondary reactions is directly related to the concentrations of the reactant ions which, in turn, increase with the total $n C_{16}$ conversion. Figure 12 and

Figure 13 show the formation of respectively $n$-hexane and iso-hexane, calculated with Equation 14, from $\mathrm{C}_{16}$ isomers and secondary cracked products at $513 \mathrm{~K}$ and $1 \mathrm{MPa}$. Linear products are initially formed out of monobranched $C_{16}$ species through $(s, s) \beta$-scission. Due to the lower activation energies for $(s, t) \beta$-scission compared to $(s, s) \beta$-scission, dibranched $\mathrm{C}_{16}$ isomers become the main reactant for $n \mathrm{C}_{6}$ formation from intermediate conversions on. The contribution of $i C_{6}$ and $C_{9}-C_{13}$ to $n C_{6}$ formation via isomerization and cracking, increases significantly at high total conversions and eventually may exceed the contribution of dibranched $C_{16}$ isomers to $n C_{6}$ formation. 
A similar observation was made for $i \mathrm{C}_{6}$. As branched cracked products cannot be directly formed out of monobranched species according to the reaction scheme, dibranched $\mathrm{C}_{16}$ isomers are initially responsible for $i C_{6}$ production. As the concentration of tribranched $C_{16}$ species increases, $(t, t) \beta$-scission gradually starts to dominate the formation of branched $C_{6}$ products. Secondary reactions become increasingly more important with the total $n C_{16}$ conversion and will finally dominate iso-hexane production.

\section{Conclusions}

The Single-Event MicroKinetic (SEMK) model originally developed for lighter alkane gasphase hydrocracking on a large-pore Pt/H-USY zeolite has successfully been extended towards another large-pore zeolite, i.e., Pt/H-beta. Shape-selective effects were found to be responsible for the restricted formation of ethyl-branched isomers and have been quantified by a $21.9 \mathrm{~kJ} \mathrm{~mol}^{-1}$ increase in the activation energy. The loss of selectivity in hydrocarbon physisorption at saturation conditions is adequately captured by the size entropy which is correlated with the carbon number and the catalyst loading. This allows to describe the effect of intermolecular interactions and packing efficiencies during the physisorption step and ultimately leads to a significant increase in reactivity of secondary products, quantified by means of a contribution analysis. A higher absolute value of about $7 \mathrm{~kJ} \mathrm{~mol}^{-1}$ for the standard protonation enthalpies for carbenium ion formation on the beta zeolite was obtained compared to the reference USY, and originates from a 
combined effect of intrinsically stronger acid sites and protonation excess. The latter effect is caused by saturation effects due to strong Van der Waals interactions between adsorbate molecules, i.e., $n$-hexadecane, and the zeolite lattice.

Full saturation of the micropores throughout an experiment implies liquid-phase like conversion and leads to an entire loss in the physisorption selectivity determined from the Henry coefficient. The methodology formulated in this work offers the possibility to accurately describe the physisorption step of a heterogeneously catalyzed reaction performed under any of the three distinguished regimes, i.e., low catalyst loadings with physisorbed species at gas-phase conditions, high catalyst loadings at gas-phase conditions and liquid-phase conditions. 


\title{
Nomenclature
}

\author{
Roman symbols \\ b model parameter vector \\ C concentration $\left[\mathrm{mol} \mathrm{kg}^{-1}\right]$ \\ $\bar{C} \quad$ average concentration $\left[\mathrm{mol} \mathrm{kg}^{-1}\right]$ \\ $C_{\mathrm{P}} \quad$ concentration of physisorbed paraffin $\left[\mathrm{mol} \mathrm{kg}{ }^{-1}\right.$ ] \\ CN carbon number \\ $E_{\text {act }} \quad$ activation energy $\left[\mathrm{J} \mathrm{mol}^{-1}\right]$ \\ $F \quad$ experimental flow rate $\left[\mathrm{mol} \mathrm{s}^{-1}\right]$ \\ $\hat{F} \quad$ calculated flow rate $\left[\mathrm{mol} \mathrm{s}^{-1}\right]$ \\ $H \quad$ Henry coefficient $\left[\mathrm{mol} \mathrm{kg}^{-1} \mathrm{MPa}^{-1}\right]$ \\ $\Delta H \quad$ enthalpy $\left[\mathrm{J} \mathrm{mol}^{-1}\right]$ \\ $K^{\text {deh }} \quad$ dehydrogenation equilibrium coefficient [MPa] \\ $\widetilde{K}^{\text {iso }} \quad$ isomerization single-event equilibrium coefficient [-] \\ $K^{\mathrm{L}} \quad$ Langmuir physisorption coefficient $\left[\mathrm{MPa}^{-1}\right]$ \\ $\widetilde{K}^{\text {pro }} \quad$ protonation equilibrium coefficient $\left[\mathrm{kg} \mathrm{mol}^{-1}\right]$ \\ $k \quad$ rate coefficient $\left[\mathrm{s}^{-1}\right]$ \\ $m \quad$ type of carbenium ion \\ $n_{e} \quad$ number of single events \\ ncar number of carbenium ions
}




\begin{tabular}{|c|c|}
\hline nobs & number of observations \\
\hline npar & number of paraffins \\
\hline nresp & number of responses \\
\hline$p$ & pressure [MPa] \\
\hline$R$ & universal gas constant $\left[\mathrm{J} \mathrm{mol}{ }^{-1} \mathrm{~K}^{-1}\right]$ \\
\hline$R$ & net rate of production $\left[\mathrm{mol} \mathrm{kg} \mathrm{s}^{-1}\right.$ ] \\
\hline$r$ & reaction rate $\left[\mathrm{mol} \mathrm{kg}^{-1} \mathrm{~s}^{-1}\right]$ \\
\hline$\Delta S$ & entropy $\left[\mathrm{J} \mathrm{mol}^{-1} \mathrm{~K}^{-1}\right]$ \\
\hline SSQ & sum of squares \\
\hline$T$ & temperature $[\mathrm{K}]$ \\
\hline$W$ & catalyst mass [kg] \\
\hline$w$ & weighing factor \\
\hline$w$ & interaction parameter [-] \\
\hline$x$ & total conversion [-] \\
\hline$Y$ & product yield [-] \\
\hline
\end{tabular}

Greek symbols

$\alpha \quad$ separation factor $[-]$

$\alpha, \alpha_{1}, \alpha_{2} \quad$ coefficients for the size entropy approximation [ $\mathrm{J} \mathrm{mol}^{-1} \mathrm{~K}^{-1}$ ]

$\boldsymbol{\beta} \quad$ real parameter vector

$\beta, \beta_{1}, \beta_{2} \quad$ coefficients for the size entropy approximation [J $\mathrm{mol}^{-1} \mathrm{~K}^{-1}$ ] 


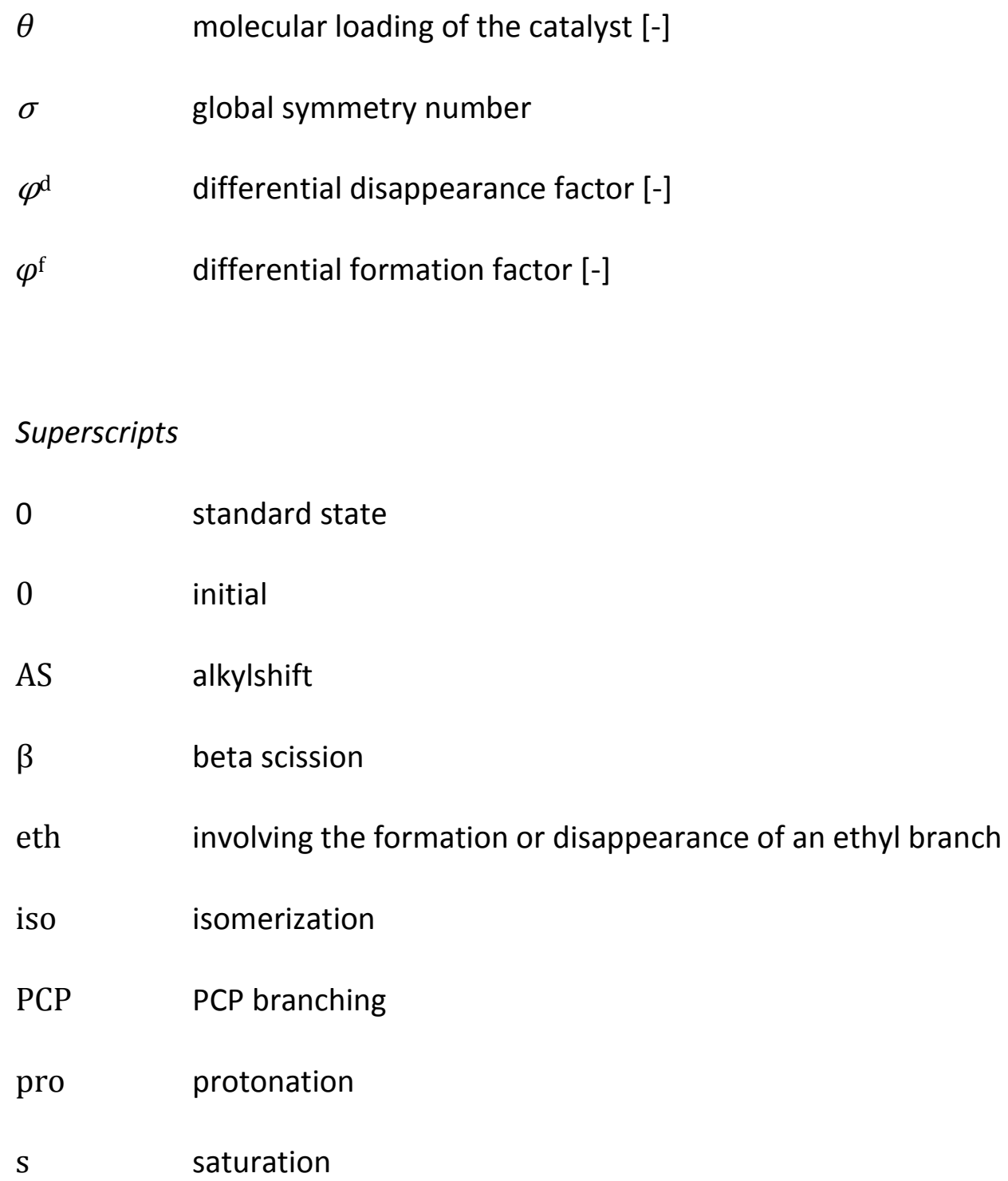




$\begin{array}{ll}\text { ads } & \text { physisorption } \\ \text { ref } & \text { reference } \\ \mathrm{O} & \text { olefin } \\ \mathrm{R}^{+} & \text {carbenium ion } \\ \mathrm{siz} & \text { size }\end{array}$




\section{Acknowledgements}

This work was funded by the European Research Institute of Catalysis and the European Community's Sixth Framework Programme. This work was also supported by the Research Board of Ghent University (BOF), the Interuniversity Attraction Poles Programme - Belgian State - Belgian Science Policy and the Long Term Structural Methusalem Funding by the Flemish Government. Financial support by the Comisión Interministerial de Ciencia y Tecnología (CICYT) of Spain through the Project CTQ2010-17988/PPQ is also gratefully acknowledged. 


\section{References}

[1] S. Mohanty, D. Kunzru, D.N. Saraf, Fuel 69 (1990) 1467-1473.

[2] J. Ancheyta, S. Sanchez, M.A. Rodriguez, Catal. Today 109 (2005) 76-92.

[3] D. Gillis, M. Van Wees, P. Zimmerman, E. Houde, J. Jpn. Petrol. Inst. 53 (2010) 33-41.

[4] V. Calemma, C. Gambaro, W.O. Parker, R. Carbone, R. Giardino, P. Scorletti, Catal. Today 149 (2010) 40-46.

[5] I. Rosetti, C. Gambaro, V. Calemma, Chem. Eng. J. 154 (2009) 295-301.

[6] P.B. Weisz, Adv. Catal. 13 (1962) 137-190.

[7] J.A. Martens, P.A. Jacobs, J. Weitkamp, Appl. Catal. 20 (1986) 239-281.

[8] A. Corma, A. Martinez, S. Pergher, S. Peratello, C. Perego, G. Bellusi, Appl. Catal. A 152 (1997) 107-125.

[9] H. Deldari, Appl. Catal. A 293 (2005) 1-10.

[10] A. Patrigeon, E. Benazzi, C. Travers, J.Y. Bernhard, Catal. Today 65 (2001) 149-155.

[11] W.M. Zhang, P.G. Smirniotis, J. Catal. 182 (1999) 400-416.

[12] F. Alvarez, F.R. Ribeiro, G. Perot, C. Thomazeau, M. Guisnet, J. Catal. 162 (1996) 179189.

[13] M. Guisnet, C. Thomazeau, J.L. Lemberton, S. Mignard, J. Catal. 151 (1995) 102-110.

[14] M.J. Remy, D. Stanica, G. Poncelet, E.J.P. Feijen, P.J. Grobet, J.A. Martens, P.A. Jacobs, J. Phys. Chem. 100 (1996) 12440-12447.

[15] J.A. Martens, G. Vanbutsele, P.A. Jacobs, J.F.M. Denayer, R. Ocakoglu, G.V. Baron, J.A.M. Arroyo, J. Thybaut, G.B. Marin, Catal. Today 65 (2001) 111-116.

[16] P.A. Jacobs, J.A. Martens, J. Weitkamp, H.K. Beyer, Faraday Discuss. 72 (1981) 353369.

[17] P. Castano, A.G. Gayubo, B. Pawelec, J.L.G. Fierro, J.M. Arandes, Chem. Eng. J. 140 (2008) 287-295.

[18] A. Lugstein, A. Jentys, H. Vinek, Appl. Catal. A 176 (1999) 119-128.

[19] A.F.P. Ferreira, M.C. Mittelmeijer-Hazeleger, A. Bliek, Adsorption 13 (2007) 105-114.

[20] M.A. Baltanas, K.K. Vanraemdonck, G.F. Froment, S.R. Mohedas, Ind. Eng. Chem. Res. 28 (1989) 899-910.

[21] G.D. Svoboda, E. Vynckier, B. Debrabandere, G.F. Froment, Ind. Eng. Chem. Res. 34 (1995) 3793-3800.

[22] G.G. Martens, G.B. Marin, J.A. Martens, P.A. Jacobs, G.V. Baron, J. Catal. 195 (2000) 253-267.

[23] J.W. Thybaut, C.S.L. Narasimhan , G.B. Marin, J.F.M. Denayer, G.V. Baron, P.A. Jacobs, J.A. Martens, Catal. Lett. 94 (2004) 81-88.

[24] C.S.L. Narasimhan, J.W. Thybaut, G.B. Marin, P.A. Jacobs, J.A. Martens, J.F.M. Denayer, G.V. Baron, J. Catal. 220 (2003) 399-413.

[25] C.S.L. Narasimhan, J.W. Thybaut, J.A. Martens, P.A. Jacobs, J.F.M. Denayer, G.B. Marin, J. Phys. Chem. B 110 (2006) 6750-6758. 
[26] J.W. Thybaut, C.S.L. Narasimhan, G.B. Marin, Catal. Today 111 (2006) 94-102.

[27] J.F.M. Denayer, G.V. Baron, Adsorption 3 (1997) 251-265.

[28] J.F.M. Denayer, A. Bouyermaouen, G.V. Baron, Ind. Eng. Chem. Res. 37 (1998) 36913698.

[29] J.F.M. Denayer, R.A. Ocakoglu, W. Huybrechts, B. Dejonckheere, P.A. Jacobs, S. Calero, R. Krishna, B. Smit, G.V. Baron, J.A. Martens, J. Catal. 220 (2003) 66-73.

[30] K.C. Park, S.K. Ihm, Appl. Catal. A 203 (2000) 201-209.

[31] A. Hassan, S. Ahmed, M.A. Ali, H. Hamid, T. Inui, Appl. Catal. A - 220 (2001) 59-68.

[32] A. Soualah, J.L. Lemberton, L. Pinard, M. Chater, P. Magnoux, K. Mojord, Appl. Catal. A 336 (2008) 23-28.

[33] Z.B. Wang, A. Kamo, T. Yoneda, T. Komatsu, T. Yashima, Appl. Catal. A 159 (1997) 119132.

[34] J.A. Martens, J. Perez-Pariente, P.A. Jacobs, Acta Phys. Chem. 31 (1985) 487-495.

[35] A.R. Pradhan, J.F. Wu, S.J. Jong, W.H. Chen, T.C. Tsai, S.B. Liu, Appl. Catal A 159 (1997) 187-209.

[36] C. Baerlocher, W.M. Meier, D.H. Olson, Atlas of Zeolite Framework Types, Elsevier, Amsterdam, 2001.

[37] A. Martinez, G. Prieto, M.A. Arribas, P. Concepcion, Appl. Catal. A 309 (2006) 224-236.

[38] A. Martinez, G. Prieto, M.A. Arribas, P. Concepcion, J.F. Sanchez-Royo, J. Catal. 248 (2007) 288-302.

[39] D.E. Mears, Chem. Eng. Sci. 26 (1971) 1361.

[40] N. Wakao, S. Kaguei, T. Funazkri, Chem. Eng. Sci. 34 (1979) 325-336.

[41] D.E. Mears, J. Catal. 20 (1971), 127.

[42] G.F. Froment, K.B. Bischoff, Chemical Reactor Analysis and Design, Wiley, New York, 1990.

[43] J.W. Thybaut, C.S.L. Narasimhan, J.F.M. Denayer, G.V. Baron, P.A. Jacobs, J.A.

Martens, G.B. Marin, Ind. Eng. Chem. Res. 44 (2005) 5159-5169.

[44] J.C. Chavarria, J. Ramirez, H. Gonzalez, M.A. Baltanas, Catal. Today 98 (2004) 235-242.

[45] H.H. Rosenbrock, Comput. J. 3 (1960) 175-184.

[46] D.W. Marquardt, J. Soc. Ind. Appl. Math. 11 (1963) 431-441.

[47] http://www.netlib.org, 23-02-2012.

[48] G.G. Martens, J.W. Thybaut, G.B. Marin, Ind. Eng. Chem. Res. 40 (2001) 1832-1844.

[49] J.M. Schweitzer, P. Galtier, D. Schweich, Chem. Eng. Sci. 54 (1999) 2441-2452.

[50] S. Ergun, Chem. Eng. Prog. 48 (1952) 89-94.

[51] J.W. Thybaut, G.B. Marin, G.V. Baron, P.A. Jacobs, J.A. Martens, J. Catal. 202 (2001) 324-339.

[52] S.W. Benson, F.R. Cruickshank, D.M. Golden, G.R. Haugen, H.E. O’Neal, A.S. Rodgers, R. Shaw, R.Walsh, Chem. Rev. 69 (1969) 279-324.

[53] C. Reid, J.M. Prausnitz, B.E. Poling, The Properties of Gases and Liquids, fourth ed., McGraw-Hill International Editions, Singapore, 1988.

[54] C.S.L. Narasimhan, J.W. Thybaut, G.B. Marin, J.A. Martens, J.F.M. Denayer, G.V. Baron, J. Catal. 218 (2003) 135-147. 
[55] J.F.M. Denayer, G.V. Baron, W. Souverijns, J.A. Martens, P.A. Jacobs, Ind. Eng. Chem. Res. 36 (1997) 3242-3247.

[56] J.F.M. Denayer, W. Souverijns, P.A. Jacobs, J.A. Martens, G.V. Baron, J. Phys. Chem. B 102 (1998) 4588-4597.

[57] M. Schenk, S. Calero, T.L.M. Maesen, T.J.H. Vlugt, L.L. Van Benthem, M.G. Verbeek, B. Schnell, B. Smit, J. Catal. 214 (2003) 88-99.

[58] J.A. Martens, P.A. Jacobs, J. Weitkamp, Appl. Catal. 20 (1986) 283-303.

[59] J.F.M. Denayer, B. De Jonckheere, M. Hloch, G.B. Marin, G. Vanbutsele, J.A. Martens, G.V. Baron, J. Catal. 210 (2002) 445-452.

[60] C.N. Satterfield, J.K. Smeets, AIChE J. 20 (1974) 618-619.

[61] B. Li, V. Calemma, C. Gambaro, G.V. Baron, J.F.M. Denayer, Ind. Eng. Chem. Res. 49 (2010) 7541-7549.

[62] R. Krishna, S. Calero, B. Smit, Chem. Eng. J. 88 (2002) 81-94.

[63] S. Calero, B. Smit, R. Krishna, J. Catal. 202 (2001) 395-401.

[64] A.L. Myers, J.M. Prausnitz, AIChE J. 11 (1965) 121-127.

[65] J.F.M. Denayer, G.V. Baron, P.A. Jacobs, J.A. Martens, Phys. Chem. Chem. Phys. 2 (2000) 1007-1014. 


\section{Figure Captions}

Figure 1 - The total $n$-hexadecane conversion, calculated via Equation 1, versus time on stream for the Pt/H-beta catalyst at $513 \mathrm{~K}, 0.5 \mathrm{MPa}$, a hydrogen-to-hydrocarbon molar ratio of 100 and at a space time of $81.4 \mathrm{~kg} \mathrm{~s} \mathrm{~mol}^{-1}$.

Figure 2 - The experimental isomerization yield as a function of the total $\boldsymbol{n}$-hexadecane conversion at varying reaction conditions; at $503 \mathrm{~K}$ (triangles), $513 \mathrm{~K}$ (squares) and $523 \mathrm{~K}$ (circles), and at $0.5 \mathrm{MPa}$ (open), $1 \mathrm{MPa}$ (grey) and $2 \mathrm{MPa}$ (black). Conversions and yields are calculated according to Equations 1 and 2.

Figure 3 -The experimental total $n$-hexadecane conversion versus space time at $503 \mathrm{~K}$ (triangles), $513 \mathrm{~K}$ (squares) and $523 \mathrm{~K}$ (circles) at $1 \mathrm{MPa}$ (grey) and $2 \mathrm{MPa}$ (black). Dashed lines, calculated with the set of parameter estimates given in Table 1 for the original model by integration of the set of ordinary differential equations (Equation 5) with production rates determined from Equations 8 and 9. Full lines, calculated with the set of parameter estimates given in Table 1 and Table 3 for the advanced model applying Equations 5, 8 and 9, and incorporating Equation 15 and Equations 21 to 23 for respectively the formation of ethyl branches and the size entropy. Conversions and yields are calculated according to Equations 1 and 2.

Figure 4 - The experimental monobranched (black circles) and multibranched (open squares) isomer yields versus total $\boldsymbol{n}$-hexadecane conversion. Dashed lines, calculated with the set of parameter estimates given in Table 1 for the orginal model by integration of the set of ordinary differential equations (Equation 5) with production rates determined from Equations 8 and 9 . Full lines, calculated with the set of parameter estimates given in Table 1 and Table 3 for the advanced model, applying Equations 5, 8 and 9, and incorporating Equation 15 and Equations 21 to 23 for respectively the formation of ethyl branches and the size entropy. Conversions and yields are calculated according to Equations 1 and 2.

Figure 5 - The experimental cracking product yields (black bars) according to the carbon number at a total n-hexadecane conversion of $75.7 \%$, at $513 \mathrm{~K}, 1 \mathrm{MPa}$ and a space time of $115 \mathrm{~kg} \mathrm{~s} \mathrm{~mol}^{-1}$; Grey bars, calculated with the set of parameter estimates given in Table 1 for the original model by integration of the set of ordinary differential equations (Equation 5) with production rates determined from Equations 8 and 9; Open bars, calculated with the set of parameter estimates given in Table 1 and Table 3 for the advanced model, applying Equations 5, 8 and 9, and incorporating Equation 15 and Equations 21 to 23 for 
respectively the formation of ethyl branches and the size entropy. Yields are calculated according to Equation 2.

Figure 6 - The experimental relative cracking product yields obtained from $\boldsymbol{n}$-hexadecane hydrocracking over Pt/H-beta (black bars) and Pt/H-USY (white bars) at a total $n$-hexadecane conversion of approximately $77 \%$, at $513 \mathrm{~K}$ (Pt/H-beta) or $528 \mathrm{~K}$ (Pt/H-USY), at $4 \mathrm{MPa}$, at a hydrogen-to-hydrocarbon molar ratio of 100 and at a space time of $226 \mathrm{~kg} \mathrm{~s} \mathrm{~mol}^{-1}$.

Figure 7 - Parity diagrams for the outlet flow rates of the mono-ethyl branched hexadecane isomers; a, calculated with the set of parameter estimates given in Table 1 for the original model by integration of the set of ordinary differential equations (Equation 5) with production rates determined from Equations 8 and 9; b, calculated with the set of parameter estimates given in Table 1 and Table 3 for the advanced model, applying Equations 5, 8 and 9, and incorporating Equation 15 and Equations 21 to 23 for respectively the formation of ethyl branches and the size entropy.

Figure 8 - The experimental undecane (black circles) and pentane (open squares) yields versus total $n$ hexadecane conversion. Dashed lines, calculated with the set of parameter estimates given in Table 1 for the original model by integration of the set of ordinary differential equations (Equation 5) with production rates determined from Equations 8 and 9. Both curves coincide. Full lines, calculated with the set of parameter estimates given in Table 1 and Table 3 for the advanced model, applying Equations 5, 8 and 9, and incorporating Equation 15 and Equations 21 to 23 for respectively the formation of ethyl branches and the size entropy. Conversions and yields are calculated according to Equations 1 and 2.

Figure 9 - The experimental $n$-octane (black circles) and iso-octane (open squares) yields versus total $n$ hexadecane conversion. Dashed lines, calculated with the set of parameter estimates given in Table 1 for the original by integration of the set of ordinary differential equations (Equation 5) with production rates determined from Equations 8 and 9. Full lines, calculated with the set of parameter estimates given in Table 1 and Table 3 for the advanced model, applying Equations 5, 8 and 9, and incorporating Equation 15 and Equations $\mathbf{2 1}$ to $\mathbf{2 3}$ for respectively the formation of ethyl branches and the size entropy. Conversions and yields are calculated according to Equations 1 and 2.

Figure 10 - Separation factors, determined from Equation 24 relative to $n$-heptane, as a function of the alkane carbon number at a temperature of $513 \mathrm{~K}$. Dashed line, calculated with the set of parameter 
estimates given in Table 1 for the original model by integration of the set of ordinary differential equations (Equation 5) with production rates determined from Equations 8 and 9. Full line, calculated with the set of parameter estimates given in Table 1 and Table 3 for the advanced model, applying Equations 5, 8 and 9, and incorporating Equation 15 and Equations 21 to 23 for respectively the formation of ethyl branches and the size entropy.

Figure 11 - Contribution analysis for the hydroconversion of hexadecane isomers, i.e., linear, monobranched, dibranched and tribranched $C_{16}$ components, and of cracking products divided into $C_{8}$-to$\mathrm{C}_{13}$ linear and branched components, and the lightest products up to carbon number 7. Numbers indicate percentage differential disappearance factors of each group of components, calculated using Equation 13, and at a total $n \mathrm{C}_{16}$ conversion of $50 \%$ at $\mathrm{T}=513 \mathrm{~K}, \mathrm{p}=1 \mathrm{MPa}$ and $W / F_{0}=115 \mathrm{~kg} \mathrm{~s} \mathrm{~mol}{ }^{-1}$. Reaction rates are calculated from Equation $\mathbf{5}$ with the set of parameter estimates given in Table 1 for Model $\mathbf{2}$ and in Table 3. Higher rates of disappearance are indicated by thicker arrows, contributions below $10 \%$ by dashed arrows.

Figure 12 - Percentage differential formation factors for $n C_{6}$ out of various components, i.e., monobranched $C_{16}$ isomers (dots), dibranched $C_{16}$ isomers (short dash), tribranched $C_{16}$ isomers (long dash) and cracked products (full). Contributions are calculated according to Equation 14 at $T=513 \mathrm{~K}, \mathrm{p}=1$ $\mathrm{MPa}$ and $W / F_{0}=115 \mathrm{~kg} \mathrm{~s} \mathrm{~mol}^{-1}$. Reaction rates are calculated from Equation 5 with the set of parameter estimates given in Table 1 and Table 3 for the advanced model.

Figure 13 - Percentage differential formation factors for $\mathrm{iC}_{6}$ out of various components, i.e., monobranched $\mathrm{C}_{16}$ isomers (dots), dibranched $\mathrm{C}_{16}$ isomers (short dash), tribranched $\mathrm{C}_{16}$ isomers (long dash) and cracked products (full). Contributions are calculated according to Equation 14 at T= 513K, p = 1 MPA and $W / F_{0}=115 \mathrm{~kg} \mathrm{~s} \mathrm{~mol}^{-1}$. Reaction rates are calculated from Equation 5 with the set of parameter estimates given in Table 1 and Table 3 for the advanced model. 